\title{
AGCM Biases in Evaporation Regime: Impacts on Soil Moisture Memory and Land-Atmosphere Feedback
}

\author{
Sarith P.P. Mahanama* ${ }^{\star \dagger} \quad$ Randal D. Koster ${ }^{\dagger}$
}

March 24, 2005 
*Goddard Earth Sciences and Technology Center, University of Maryland, Baltimore County,

Baltimore, MD 21250, USA.

${ }^{\dagger}$ NASA Goddard Space Flight Center,

Code 610.1, Global Modeling Assimilation Office,

Greenbelt, MD 20771, USA.

Corresponding author address:

Sarith Mahanama,

NASA Goddard Space Flight Center,

Code 610.1, Global Modeling and Assimilation Office,

Greenbelt, MD 20771, USA.

Email: sarith@janus.gsfc.nasa.gov

Tel: (+1) 301-614-5667, FAX: (+1) 301-614-6297

revised manuscript to the Journal of Hydrometeorology 


\section{Abstract}

Because precipitation and net radiation in an atmospheric general circulation model (AGCM) are typically biased relative to observations, the simulated evaporative regime of a region may be biased, with consequent negative effects on the AGCM's ability to translate an initialized soil moisture anomaly into an improved seasonal prediction. These potential problems are investigated through extensive offline analyses with the Mosaic land surface model (LSM). We first forced the LSM globally with a 15-year observations-based dataset. We then repeated the simulation after imposing a representative set of GCM climate biases onto the forcings - the observational forcings were scaled so that their mean seasonal cycles matched those simulated by the NSIPP-1 (NASA Global Modeling and Assimilation Office) AGCM over the same period.The AGCM's climate biases do indeed lead to significant biases in evaporative regime in certain regions, with the expected impacts on soil moisture memory timescales. Furthermore, the offline simulations suggest that the biased forcing in the AGCM should contribute to overestimated feedback in certain parts of North America - parts already identified in previous studies as having excessive feedback. The present study thus supports the notion that the reduction of climate biases in the AGCM will lead to more appropriate translations of soil moisture initialization into seasonal prediction skill. 


\section{Introduction}

Evaporation underlies land-atmosphere interaction. Evaporation (and associated variations in sensible heat flux) can effectively translate a soil moisture anomaly into an anomaly in atmospheric boundary layer conditions and, as a result, into a precipitation anomaly. The potential feedback of soil moisture on precipitation through evaporation has been the subject of several theoretical studies (e.g., Entekhabi et al., 1991; Rodriguez-Iturbe et al., 1991) and observational studies (e.g., Namias, 1959; Barnston and Schickedanz, 1984; Findell and Eltahir, 1997; Salvucci et al., 2002).

Model-based feedback studies are especially prevalent. In some ways, models (e.g., atmospheric general circulation models, or AGCMs) are particularly valuable tools for land-atmosphere feedback studies, since they offer two key advantages: (a) they provide complete suites of data covering all aspects of the land-atmosphere connection, including quantities (such as evaporation rates) that are difficult to measure in nature at large scales, and (b) the physics in a model can be artifically altered for sensitivity studies, allowing important mechanisms to be isolated and quantified. The impact of soil moisture on precipitation has been established in numerous atmospheric general circulation model (AGCM) studies (e.g., Koster et al., 2000, 2004; Liu and Avissar, 1999a,b; Dirmeyer, 2000, 2003; Dirmeyer et al., 2003; Douville, 2003; Schubert et al., 2004).

Intuitively, for such modeling studies to be effective, the background climate for an AGCM-based land-atmosphere interaction study should be as realistic as possible. Any free-running climate modeling system, however, is prone to biases. Gates et al. (1999) quantified the biases in 31 modeled climates as part of the Atmospheric 
Model Intercomparison Project (AMIP). Gates et al. (1999) found that the models are generally too dry by more than $20 \%$ over large regions of the major precipitation zones, and are also too wet in the major dry zones in both DJF and JJA. Gates et al. (1999) also noted that climate biases may result from errors in the parameterization of clouds and their radiative interactions, in the parameterization of convection and precipitation, and in the representation of land surface and hydrologic processes.

Simply put, climate biases in AGCMs are a fact of life. Given their presence, one may naturally ask how they affect the conclusions of model-based land-atmosphere feedback studies. We address this question in this paper. We focus in particular on the aspects of feedback relevant to seasonal prediction - relevant to the idea that knowledge of soil moisture anomalies at the beginning of a seasonal forecast period could result in increased skill in predicted precipitation. Koster and Suarez (2003) noted two separate elements to the impact of feedback on forecast skill: (a) the initialized anomaly must be 'remembered' well into the forecast period, and (b) the atmosphere (e.g., precipitation-generating processes) must respond in a predictable way to the soil moisture anomaly. The simulation of both elements, it turns out, is affected significantly by climate biases, particularly by the way the evaporation regime (the degree to which evaporation is controlled by soil moisture supply versus evaporation demand) is biased due to biases in simulated precipitation and incoming radiation.

Section 2 provides needed background on evaporation regime and its relationship to soil moisture. Section 3 then shows how the climate biases in a representative AGCM can lead to biases in the simulated evaporation regime. Sections 4 and 5 treat respectively the impact of evaporation regime biases on simulated soil moisture 
memory and the response of precipitation to soil moisture anomalies.

\section{Background: Sensitivity of Evaporation to Soil Moisture in an AGCM}

The Land Surface Model (LSM) in a climate modeling system computes evaporation fluxes as part of the surface water and energy balance calculation using complex parameterizations typically employing numerous state variables and parameters. Nevertheless, everything else being equal, evaporation intuitively should either increase monotonically with soil moisture or be insensitive to it. The full nature of the evaporation-soil moisture relationship is illustrated by a revisit to the idealized experiment of Mahanama and Koster, (2003), which investigated LSM behaviors under a wide range of climates. In the version of the experiment examined here, we focus on a surface element having a baresoil fraction of $30 \%$, loam soil, and moderate topography. Atmospheric forcing data for a 10,000-month perpetual July experiment was prepared using PILPS2c (Project for Intercomparison of Landsurface Parameterization Schemes Phase 2c, Wood et al., 1998) July-1979 forcings for the chosen location. A 10,000-month time series of monthly total precipitation was then randomly generated with values ranging from 15 to $630 \mathrm{~mm}$ and with a mean value of $180 \mathrm{~mm}$. The monthly total precipitation was temporally disaggregated using the sub-monthly distribution of the PILPS-2c July-1979 precipitation for the same surface element. Then, the Mosaic LSM (Koster and Suarez 1996) was forced for 10,000 months using the prepared precipitation time series along with other PILPS2c atmospheric forcings (see Mahanama and Koster 2003, for full 
details). The same experiment was repeated 4 times for four different vegetation biomes, evergreen broadleaf, deciduous broadleaf, needle leaf, and grassland.

Scatter plots of evaporation efficiency $\left(E / R_{n e t}\right.$, where $E$ is total evaporation (including transpiration, baresoil evaporation and interception loss) and $R_{\text {net }}$ is net radiation) versus the degree of saturation of soil moisture (soil wetness) in the soil column $(W)$ were made separately for the four experiments using daily output. The scatter in each plot is significant, but a simple binning procedure reveals an underlying relationship. Figure 1 shows this relationship for the four experiments. All four vegetation biomes show a common behavior: in drier situations, evaporation efficiency is strongly sensitive to soil moisture (measured as a wetness), whereas in wetter situations, the sensitivity is diminished - the slope $(c)$ of the $E / R_{\text {net }}$ versus soil moisture relationship is smaller. This behavior is not unexpected - in wetter climates, evaporation is controlled more by atmospheric demand than by soil moisture availability. Indeed, the basic shape of the curves in Fig. 1 is consistent with decades of understanding regarding soil moisture controlled versus atmosphere controlled evaporation regimes (e.g Manabe, 1969; Budyko, 1974; Eagleson, 1978).

Note that an idealized experiment with highly diverse rainfall forcing was used to generate the curves in Figure 1 because the range of soil moistures achieved in a GCM simulation is typically limited to a small fraction of the total range. Consider the aforementioned relationship for grassland in Figure 2. Overlaid on the plot is a representative soil moisture range from a AGCM simulation - the range for a particular grid cell with intermediate soil moisture (mean soil moisture as a wetness $=0.45)$. The plotted range is equal to twice the simulated standard deviation of soil moisture at that point. 
The ranges typically achieved are small enough, relative to the total possible range, that a single slope (e.g. that of the dashed line in the figure) can effectively characterize the local acting evaporation sensitivity to soil moisture at the given point. Fitting a single slope to simulated pairs of evaporation efficiency and soil moisture values at a grid cell has indeed proven an effective way of characterizing the behavior of a land surface model in a climatic regime. Koster and Milly (1997) used such fitted slopes to estimate annual evaporation rates across a variety of models. Koster and Suarez (2001) used such a slope to characterize soil moisture memory, and Koster et al., (2004) used it to characterize precipitation response to soil moisture anomalies. In fact, these latter two studies together imply an interesting balance required for the slope in the context of precipitation prediction. For an initial soil moisture anomaly to affect a future precipitation rate, the effective slope cannot be too large, for then the soil moisture memory would be too low, and the slope cannot be too small, for then evaporation (and thus precipitation) would not be sensitive to the soil moisture anomaly.

The ability of a single slope to characterize the sensitivity of evaporation efficiency to soil moisture and the relevance of this slope to key aspects of the prediction problem suggests an important question, alluded to in the introduction. The question is illustrated in Figure 3: can a bias in the AGCM's climate forcing lead to a bias in the acting slope (i.e. in the region's evaporative regime), a bias that can in turn negatively affect the memory and feedback characteristics of the region relevant to prediction? This question is addressed quantitatively in the next three sections. 


\section{Effect of Climate Bias on Evaporative Regime}

To quantify the impact of climate bias on evaporative regime, a series of global offline experiments was performed with the Mosaic land surface model. The Earth's land surface was divided into a somewhat unusual grid, a set of 36,716 contiguous hydrologic catchments established from high-resolution (1 km) digital elevation data (Verdin and Verdin, 1999). The average size of these surface elements is $3,800 \mathrm{~km}^{2}$. We chose this grid for convenience and efficiency; it allowed us to take advantage of the experimental set-up already employed by Mahanama and Koster (2003). The results of the present analysis would invariably be the same if we employed a rectangular grid. Land cover and soil hydraulic properties for the surface elements were derived from a variety of recent global datasets: vegetation classification was derived using the $1 \mathrm{~km}$ land cover characteristics of Belward et al. (1999), and soil texture classification came from the 5'x5' global maps of Reynolds et al., (1999).

Berg et al. (2004) merged European Center for Medium-Range Weather Forecast (ECMWF) global reanalyses of atmospheric forcings with observed fields of precipitation and radiation to produce a global, 0.5-degree, 6-hourly forcing dataset. In our earlier study, we interpolated this forcing (here after referred to as the "OBS forcing") onto the catchment grid and then forced the Mosaic LSM over the period 1979-93 (see Mahanama and Koster, 2003 for details). The Mosaic LSM produced,

as a result, global fields of evaporation, net radiation, and soil moisture - enough information to determine, global fields of the sensitivity of the evaporation efficiency (E/Rnet) to soil moisture. The map of this sensitivity - the slope $c$-during the period June through August is shown in the top left panel of Figure 4. Again, throughout this paper, this slope is used to characterize the evaporative regime 
of the land surface - high values of $c$ imply that evaporation is moisture-limited, whereas low values imply that it is more atmosphere-limited.

For the present study, we also repeated this offline experiment after imposing GCM climate biases on the OBS forcings - the total precipitation, convective precipitation, downward shortwave radiation and downward longwave radiation in the OBS dataset were scaled so that their mean seasonal cycles matched those simulated by the NSIPP-1 atmospheric GCM over the same period (1979-93).

The GCM climate biases are significant. Figure 5a shows the global distribution of the imposed precipitation biases, determined by subtracting the average June-July-August (JJA) precipitation in the OBS dataset from that of the GCM's climatology. Large positive biases (over-estimated precipitation in the GCM) can be seen in central America, over the Amazon basin, and in parts of southern Asia. Negative biases are mainly observed in other tropical land areas. Figure $5 \mathrm{~b}$ shows the bias in the sum of downward solar and longwave radiation, again computed for JJA by substracting the OBS data values from the GCM climatology. The downward radiation forcing in the GCM exceeds that in the observations over much of the globe. Both precipitation and net radiation biases collectively determine the operating climate regime at any land element, so it is possible that the effects of a precipitation bias are being cancelled out by a net radiation bias at some locations. The dryness index $\left(R_{n e t} / \lambda P\right.$, where $\lambda$ is the latent heat of vaporization and $P$ is precipitation, see Budyko, 1974) is in some ways, a more representative index of the operating climate regime. Figure $5 \mathrm{c}$ shows the global distribution of AGCM biases in dryness index.

The sensitivity of evaporation efficiency to soil moisture (the slope $c$ ) derived 
from the biased forcing experiment is shown in Figure 4b. Figure 4c shows the global distribution of the differences in the slopes obtained from the two experiments - the change in the sensitivity induced by biased atmospheric forcings. The forcing biases have clearly caused slope changes throughout the globe. Why do the slope differences occur where they do in Figure 4c? To a large extent, the plotted differences in the figure are consistent with the dryness index biases shown in Figure 5c: higher $c$ values tend to be found in regions where the climate regime has shifted to a drier climate (e.g., in the central United States and southeast Asia). Figure 6 shows the underlying relationships more clearly. Plotted in the figure are bin curves showing, for different soil moisture levels, how differences in the slope $c$ relate to biases in forcing, as characterized by bias-induced differences in dryness index. (Note that a fair amount of scatter is hidden by the binning process.) For relatively high soil moisture (average degree of saturation, $w$, greater than 0.4 ), a decrease in dryness index, which tends to make the soil even wetter, has little effect on $c$. In essence, for high moisture contents, atmospheric demand controls the evaporation, meaning that the slope is already close to zero; biases that make the soil even wetter keep it at zero. An increase in the dryness index, however, dries the soil and thus brings evaporation into the soil-controlled regime, inducing a positive slope. Thus, for wet soils experiencing an increase in dryness index, the slope differences in Figure 6 are positive. The reverse logic applies for dry soils ( $w$ less than 0.2): climate biases induce a large reduction in slope only when they make the soil moisture much wetter through a decrease in dryness index, pushing evaporation into the atmosphere-controlled regime.

As discussed in later sections, these slope biases can have important implications 
for soil moisture memory and land-atmosphere feedback characteristics in the GCM. In some areas, the slope biases are indeed large enough to force the regions altogether into the wrong evaporative regime. For discussion purposes, assume that the slope $\mathrm{c}=1.0$ serves as the transition point between climates with evaporation rates controlled by soil moisture supply (dry climates) and those with rates controlled by atmospheric demand (wet climates). The choice of this arbitrary (but representative - other choices in the neighborhood of $c=1$ would give similar patterns) value allows us to determine, through a comparison of the slopes obtained in the two experiments, where the biases in the coupled modeling system (in the AGCM) lead to an improper shift from one evaporative regime to the other (at least in the context of the modeling system used). Figure $4 \mathrm{~d}$ shows in red those regions that are incorrectly treated as soil moisture controlled regions in the GCM. Similarly, the blue areas in the figure are where the GCM incorrectly controls evaporation through atmospheric demand. We emphasize, however, that a full regime shift is not necessary for the slope bias to have an important impact on the predictability elements.

\section{Memory Analysis}

Here we examine how a bias in the evaporation sensitivity slope can effect the simulated soil moisture memory. Koster and Suarez (2001) and Mahanama and Koster (2003) showed that simulated soil moisture memory can be well approximated with the equation: 


$$
\rho=\frac{\sigma_{w_{n}}}{\sigma_{w_{n+1}}}\left[\frac{2-\frac{c \overline{R_{n}}}{C_{s}}-\frac{a \overline{P_{n}}}{C_{s}}}{2+\frac{c \overline{R_{n}}}{C_{s}}+\frac{a \overline{P_{n}}}{C_{s}}}+\frac{\operatorname{cov}\left(w_{n}, F_{n}\right)}{\sigma_{w_{n}}{ }^{2}}\right],
$$

where $n$ is the month of the year, $w$ is the soil wetness, $C_{s}$ is the column's water holding capacity, $\overline{R_{n}}$ and $\overline{P_{n}}$ are the accumulated net radiation and precipitation during the month, $c$ is the slope of the evaporation efficiency versus soil moisture relationship, $a$ is the slope of the runoff efficiency versus soil moisture relationship, and $F_{n}$ is a particular combination of forcing and model parameters. Equation 1 is, in essence, a generalization of the memory equation devised by Delworth and Manabe (1988); it implies that the memory is controlled by four aspects of the system: (a) the seasonality of the atmospheric forcing, (b) the sensitivity of evaporation to soil moisture, (c) the sensitivity of runoff to soil moisture, and (d) persistence in atmospheric forcing, as perhaps induced through land-atmosphere feedback. The "explicit" form of this semi-explicit equation,

$$
\rho=\frac{\sigma_{w_{n}}}{\sigma_{w_{n+1}}}\left[1-\frac{c \overline{R_{n}}}{C_{s}}-\frac{a \overline{P_{n}}}{C_{s}}+\frac{\operatorname{cov}\left(w_{n}, F_{n}\right)}{\sigma_{w_{n}}{ }^{2}}\right]
$$

is less numerically dependable but shows a little more clearly the relationship between soil moisture memory and evaporative regime, as characterized by the slope c. Simply put, as the slope $c$ increases - as evaporation becomes more sensitive to soil moisture - soil moisture memory decreases. 
Biases in $c$ associated with GCM climate biases should thus produce biases in memory. Is this seen in the results? Figure 7a shows the global distribution of onemonth lagged autocorrelation in soil moisture as produced from the offline simulation using the OBS forcings. (These are the actual autocorrelations, not those estimated with the equations above.) The corresponding field in Figure $7 \mathrm{~b}$ was generated from the simulation using biased forcing. Figure 7c shows the differences between the two fields; it thus shows the biases in memory induced by the biases in the forcings. Soil moisture memory in the AGCM is apparently biased low (at least subject to the physics imposed in the LSM) in the Great Plains and Pacific Northwest of the United States, around the Bay of Bengal, and across a thin zonal band in Central Asia. The memory is biased high in eastern Asia and in parts of the Sahel.

A comparison of Figures 7c and $4 c$ is suggestive - memory tends to be biased low in areas where the slope $c$ is biased high. This is quantitatively demonstrated with the scatter plot in Figure 8, in which bias in autocorrelation is plotted against bias in $c$. Although the scatter is large $\left(r^{2}=0.24\right)$, the underlying relationship is clear and statistically significant - soil moisture memory tends to increase when the slope $c$ decreases.

The impact of the GCM climate biases on the simulated soil moisture memory is now analyzed to isolate the impact of each component forcing. Three supplemental offline global simulations were performed with the Mosaic LSM to determine the impact of (1) biased downward shortwave radiation alone, (2) biased downward longwave radiation alone, and (3) biased precipitation alone on soil moisture memory.

Global fields of soil moisture memory were computed using the JJA simulations 
for each of these supplemental experiments, and each memory field was compared to that produced with the unbiased OBS forcing. The resulting biases in soil moisture memory are plotted side-by-side with biases in $c$ values for each of the supplemental experiments (Fig. 9). Comparison of the panels on the left-hand side in Figure 9 (a, c, and e) shows that the GCM precipitation biases are responsible for most of the biases in simulated memory. Similarly, the panels on the right-hand side of the figure show that the biased precipitation causes most of the bias in the operating evaporation regime. A comparison of Fig. 9f and Fig. 5a (GCM precipitation bias) further underscores how an excessive precipitation can force the evaporation system into a more atmosphere controlled regime.

We note in addition that changes in runoff efficiency could also impact the memory, as indicated by equations 1 and 2. Because the emphasis of this paper is on the sensitivity of evaporation to soil moisture, we do not elaborate the runoff effects here.

\section{Analysis of Atmospheric Response}

In the previous section, we discussed the impact of GCM climate biases on simulated soil moisture memory. Characterizing the impact of the biases on precipitation's responsiveness to soil moisture anomalies is also of interest - for a soil moisture initialization to provide skill to a seasonal precipitation forecast, both soil moisture memory and precipitation responsiveness are needed. Here, since offline simulations are used to characterize evaporation regime biases, their impacts on precipitation responsiveness are examined indirectly.

Using a 50-year observational precipitation data set covering the United States, Koster 
et al., (2003) found indirect evidence of land-atmosphere feedback in nature, i.e., evidence that soil moisture anomalies affect precipitation. Here, we reproduce from that study the autocorrelation in time of precipitation (between twice removed pentad totals - e.g. correlation between precipitation amounts in 1-5 and 11-15 July, between those in 6-10 and 16-20 July and so on.) for the AGCM in July (Figure 10a) and for observations in July (Figure 10b). The autocorrelations are an indication of feedback (see Koster et al. 2003, for details). Differences in precipitation autocorrelation (AGCM minus observed) are plotted in Figure 10c. The AGCM precipitation correlations are clearly excessive over much of the United States, indicating that the simulated feedback is too strong. Nevertheless, the presence of autocorrelations in the observations does suggest some real-world feedback.

Koster and Suarez, (2003) identified three main factors controlling the response of precipitation to soil moisture anomalies: (1) the size of the soil moisture anomaly, (2) the product of the mean net radiation $\left(R_{n e t}\right)$ and the slope of the evaporation efficiency versus soil moisture relationship ( $c$ ) and (3) the convective fraction. According to Koster and Suarez, (2003) each of these factors must be sufficiently large for land-atmosphere feedback to occur. The second factor, of course, is directly related to the evaporative regime.

Figure 10d shows the bias induced differences in the slope $c$ (i.e. in the evaporative regime) over the United States (zoomed-in from Figure 4c). Comparing Figs.(10c) and (10d) shows that the region where feedback is excessive largely overlaps the region where the slope $c$ is excessive - i.e. the region where, according to the arguments of Koster and Suarez (2003), the feedback should indeed be excessive. The comparison of Figures 10c and 10d does not, of course, constitute proof 
that AGCM climate biases in the central United States lead to excessive feedback there. The feedback could be too large, for example, because of the convection and boundary layer parameterizations employed in the model. Still, given the findings of Koster and Suarez (2003), a correction of the climate biases in the central United States should adjust the feedback strength in the proper direction.

\section{Discussion and Summary}

In this paper, we investigated the impact of AGCM climate biases on the sensitivity of evaporation to soil moisture. We then examined how bias in the evaporation sensitivity can in turn affect soil moisture memory and land-atmosphere feedback.

Our experiments were performed offline for a very simple reason: we needed to characterize the evaporation sensitivity under unbiased climatic forcing, which is next to impossible to achieve in a free-running coupled simulation. Arguably, the offline nature of the experiments limits our analysis. It certainly limits our examination in section 5 of precipitation response to soil moisture variations, for while a positive evaporation anomaly may induce a positive precipitation anomaly through land-atmosphere feedback, as assumed in the analysis, it can conceivably, under some conditions, increase atmospheric stability and thus cause a decrease in precipitation. An offline simulation cannot, of course, predict the direction of the impact. Still, any predictable impact (positive or negative) of soil moisture on precipitation in a seasonal forecast system will depend on how sensitive evaporation, as a proxy for the full energy balance, is to variations in soil moisture, and quantifying this sensitivity and its bias is the key focus of this paper. Note that the offline framework is fully adequate for our analysis of the impacts of climate bias on soil 
moisture memory, a key element of land-atmosphere interaction.

Given the complexity of the interwoven physical processes being modeled, climate biases will be found in any modeling system. Those examined here, from a specific climate model, are representative. We do not attempt here to identify the sources of the climate biases. The biases have many sources; indeed, biases in precipitation and radiation can be induced by the land model itself through land-atmosphere feedback. The land model used has been tested offline in a series of experiments under the Project for the Intercomparison of Land surface Parameterization Schemes (PILPS) (e.g., Chen et al., 1997, Wood et al., 1998, Liang et al., 1998); its own biases are representative of LSMs in general.

Throughout this paper, the sensitivity of evaporation efficiency to soil moisture in an LSM is characterized with the slope $c$, an empirically fitted quantity computed at each land element using output from extensive model simulations. Figure $4 \mathrm{c}$ in section (3) demonstrates that existing AGCM biases affect the slope $c$ and thus the operating evaporative regime in varying degrees. Figure $4 \mathrm{~d}$ shows that in some regions of the globe, the climate biases fully shift the evaporative regime from being atmosphere-controlled to soil-moisture controlled or vice-versa. Figures $5 \mathrm{c}$ and 6 show that the geographical variations in the biases of the slope $c$ are determined in large part by the geographical variations in the dryness index bias, defined in large part by the precipitation and downwelling radiation biases in the model.

The connection between biases in evaporative regime and simulated soil moisture memory was explored in section (4). Figure 8 shows that, in general, a reduction in evaporation sensitivity (i.e., in the slope $c$ ) leads to an increase in soil moisture memory, as expected from the analytical treatment of Koster and Suarez (2001). The 
biases in soil moisture memory have important implications for seasonal precipitation forecasts in a coupled modeling system. An overly low soil moisture memory, for example, will improperly limit the effectiveness of the soil moisture initialization.

The impact of biases in evaporative regime on the responsiveness of precipitation to soil moisture anomalies was explored in section (5). Figure 10 shows a connection between excessive land-atmosphere interaction in the AGCM examined and a biasinduced excess in the slope $c$. Elimination of climate biases in the central United States should reduce the excessive feedback, though perhaps not eliminate it.

Forcing the LSM globally offline in this analysis is computationally much less expensive than employing the full atmospheric GCM, yet it still allows us to emulate land surface processes as they would occur in the coupled system. The approach used here can be used by any atmospheric GCM group to examine inexpensively the impacts of their own biases on forecast skill. Ongoing efforts, such as the Global Soil Wetness Project (Dirmeyer et al., 2000), the Global Land Data Assimilation System (Rodell et al. 2004), and the Land Information System (LIS), in which numerous LSMs are run offline globally with atmospheric forcings, could provide the framework for enhanced explorations of the impact of AGCM biases on the elements of prediction.

\section{Acknowledgments}

This research was supported by funding from the Earth Science Enterprise of NASA Headquaters through the EOS-Interdisciplinary Science Program and the NASA Global Modeling and Assimilation Office (GMAO). The NASA Center for Computational Sciences provided computational resources for the global off-line simulations. 
Phil Pegion provided the NSIPP-1 AGCM seasonal climatology. We thank three anonymous reviewers for constructive comments. 


\section{References}

Barnston, A. G., and P. T. Schickedanz, 1984: The effect of irrigation on warm season precipitation in the Southern Great Plains. J. Climate Appl. Meteor., 23, 865-888.

Belward, A. S., J. E. Estes, and K. D. Kline, 1999: The IGBP-DIS 1-Km LandCover Data Set DISCover: A Project Overview: Photogrammetric Engineering and Remote Sensing, v. 65, no. 9, p. 1013-1020.

Berg, A. A., J. S. Famiglietti, M. Rodell, U. Jambor, S. L. Holl, R. H. Reichle, and P. R. Houser, 2004: Development of a hydrometeorological forcing data set for global soil moisture estimation. J. Geophys. Res., in revision.

Budyko, M. I., 1974: Climate and Life, Academic Press, New York, 508p.

Chen, T., and coauthors, 1997: Cabauw experimental results from the Project for Intercomparison of Land-surface Parameterization Schemes (PILPS), J. Climate, 10, 1194-1215.

Delworth, T. L., and S. Manabe, 1988: The influence of potential evaporation on the variabilities of simulated soil wetness and climate. J. Climate, 1, 523-547.

Dirmeyer, P. A.,2000: Using a global soil wetness dataset to improve seasonal climate simulation. J. Climate, 13, 2900-2922.

Dirmeyer, P. A., 2003: The role of the land surface background state in climate predictability. J. Hydrometeor., 4, 599-610.

Dirmeyer, P. A., M. J. Fennessy, and L. Marx, 2003: Low skill in dynamical prediction of boreal summer climate: grounds for looking beyond sea surface temperature. J. Climate, 16, 995-1002. 
Douville, H., 2003: Assesing the influence seasonal climate variability with AGCMs. J. Hydrometeor., 4, 1044-1066.

Eagleson, P. S., 1978: Climate, soil and vegetation, 4, The expected value of annual evapotranspiration. Water Resour. Res., 14, 731-739.

Entekhabi, D., I. Rodriguez-Iturbe, and R. L. Bras, 1992: Variability in large-scale water balance with land surface-atmosphere interaction. J. Climate, 5, 798-813.

Findell, K. L., and E. A. B. Eltahir, 1997: An analysis of soil moisture-rainfall feedback, based on direct observations from Illinois. Water Resour. Res., 33, 725735.

Gates, W. L., and co-authors, 1999: An overview of the results of the Atmospheric Model Intercomparison Project (AMIP I). Bull. Amer. Meteor. Soc., 80, 29-55.

Global Soil Wetness Project-2 (GSWP-2), 2002: The Second Global Soil Wetness Project Science and Implementation Plan. International GEWEX Project Office,IGPO Publication Series No. 37, 65 pp.

Koster, R. D., and M. J. Suarez, 1996: Energy and water balance calculations in the MOSAIC LSM. NASA Tech. Memo. 104606, Vol. 9, 60 pp.

Koster, R. D., and P. C. D. Milly, 1997: The interplay between transpiration and runoff formulations in land surface schemes used with atmospheric models. $J$. Climate, 10, 1578-1591.

Koster, R. D., M. J. Suarez, and M. Heiser, 2000: Variance and predictability of precipitation at seasonal-to-interannual timescales. J. Hydrometeor., 1, 26-46.

Koster, R. D., and M. J. Suarez, 2001: Soil moisture memory in climate models. J. Hydrometeor., 2, 558-570.

Koster, R. D., and M. J. Suarez, 2003: Impact of land surface initialization on seasonal precipitation and temperature prediction. J. Hydrometeor., 4, 408-423. 
Koster, R. D., M. J. Suarez, R. W. Higgins, and H. M. V. den Dool, 2003: Observational evidence that soil moisture variations affect precipitation. Geophy. Res. Lett., 30(5), 1241, doi:10.1029/2002GL016571.

Koster, R. D., M. J. Suarez, P. Liu, U. Jambor, A. Berg, M. Kistler, R. H. Reichle, M. Rodell, and J. Famiglietti, 2004: Realistic initialization of land surface states: Impacts on subseasonal forecast skill. J. Hydrometeor., 5, 1049-1063.

Land Information System (LIS): http://lis.gsfc.nasa.gov

Liang, X., and co-authors, 1998: The Project for Intercomparison of Land-surface parameterization Schemes (PILPS) Phasc 2(c) Red-Arkansas Rivcr Basin experiment: 2. Spatial and temporal analysis of energy fluxes. Global and Planetary Change, 19, 137-159.

Liu, Y., and R. Avissar, 1999a: A study of persistence in the land-atmosphere system using a general circulation model and observations. J. Climate, 12, 2139-2153.

Liu, Y., and R. Avissar, 1999b: A study of persistence in the land-atmosphere system using a fourth order analytical model. J. Climate, 12, 2154-2168.

Mahanama, S. P. P., and R. D. Koster, 2003: Intercomparison of soil moisture memory in two land surface models.J. Hydrometeor., 4, 1134-1146.

Manabe, S., 1969: Climate and ocean circulation I: The atmospheric circulation and the hydrology of the earth's surface. Mon. Wea. Rev., 97, 739-774.

Namias, J., 1959: Persistence of mid-tropospheric circulations between adjacent months and seasons. The Atmosphere and the Sea in Motion, Rossby Memorial Volume, B. Bolin, Ed., Amer. Meteor. Soc., 240-248.

Reynolds, C. A., T. J. Jackson, and W. J. Rawls, 1999: Estimating Available Water Content by Linking the FAO Soil Map of the World with Global Soil Profile Databases and Pedo-transfer Functions. Proceedings of the AGU 1999 Spring 
Conference, Boston, MA. May 31-June 4, 1999.

Rodell, M., P. R. Houser, U. Jambor, J. Gottschalck, K. Mitchell, C.-J. Meng, K. Arsenault, B. Cosgrove, J. Radakovich, M. Bosilovich, J. K. Entin, J. P. Walker, D. Lohmann, and D. Toll, The Global Land Data Assimilation System, Bull. Amer. Meteor. Soc., 85 (3), 381-394, 2004.

Rodriguez-Iturbe, I., D. Entekhabi, and R. L. Bras, 1991: Nonlinear dynamics of soil moisture at climate scales. Part 1: Stochastic analysis. Water Resour. Res., 27, 1899-1906.

Verdin, K. L., and J. P. Verdin, 1999: A topological system for delineation and codification of the Earth's river basins, J. Hydrol., 218, 1-12.

Salvucci, G. D., J. A. Saleem, and R. Kaufmann, 2002: Investigating soil moisture feedbacks on precipitation with tests of Granger causality. Adv. Water Resour., 25, 1305-1312.

Schubert, S., M. J. Suarez, P.J. Pegion, R. D. Koster, and J. T. Bacmeister, 2004: On the cause of the 1930s dust bowl. Science, 303, 1855-1859.

Wood, E. F., and co-authors, 1998: The Project for Intercomparison of Land-surface parameterization Schemes (PILPS) Phase 2(c) Red-Arkansas River Basin experiment: 1. Experiment description and summary intercomparisons. Global and Planetary Change, 19, 115-135. 


\section{Figure Captions}

Figure 1: Evaporation efficiency versus the degree of saturation of soil moisture for four different vegetation biomes. The daily values from each idealized, 10,000-month perpetual July experiment have been binned.

Figure 2: Soil moisture statistics for a representative AGCM grid cell overlaid on the bottom right panel of Figure 1. The solid vertical line shows a mean soil moisture wetness of 0.45 for this grid cell, while the dashed lines delimit a range standard deviation of soil moisture there. The sloping dashed line shows that a linear relationship can approximate the soil moisture-evaporation relationship within the cell.

Figure 3: Schematic showing the potential impact of climate biases on the sensitivity of evaporation efficiency to soil moisture.

Figure 4: (a) Global map of the slope $c$ based on the offline simulation using OBS forcings (b) Same, but for the offline simulation using biased GCM forcings, (c) Differences: $c$ from biased forcings minus $c$ from OBS forcings, (d) regions where biases induce an overall shift in evaporation regime, assuming transition $c$ value of 1.0. - Blue: indicates a transition to an atmosphere controlled regime, and red indicates a transition to a soil moisture controlled regime.

Figure 5: (top) AGCM biases in mean precipitation (JJA, in mm/day). (middle) AGCM biases in the sum of downward shortwave and downward longwave radiation (JJA, in $\left.\mathrm{W} / \mathrm{m}^{2}\right)$, (bottom) GCM biases in dryness index $\left(R_{\text {net }} / \lambda P\right.$, where $\lambda$ is the latent heat of vaporization).

Figure 6: Differences in the slope $c$ versus biases in forcings (as characterized by biases in dryness index) for different soil moisture levels: lines were plotted through 
simple binning.

Figure 7: (a) One-month-lagged autocorrelations of soil moisture, $\rho$, as obtained from the offline simulation with OBS forcings, (b) Same, but as obtained with the offline simulation using the biased forcings, (c) Differences: resulting biases in the one-month-lagged autocorrelation of soil moisture.

Figure 8: Scatter plot showing how biases in the slope $c$ relate to biases in the one-month-lagged autocorrelations of soil moisture $(\rho)$.

Figure 9: The impact of each component forcing bias on soil moisture memory ( $\rho$ ). (a) Differences in $\rho$ due to biased AGCM shortwave radiation, (b) Differences in the slope $c$ due to biased AGCM shortwave radiation, (c) and (d) Same, but for biased AGCM downward longwave radiation, (e) and (f) Same, but for biased AGCM precipitation.

Figure 10: (a) Correlations between twice-removed pentad precipitation, as produced by the AGCM in July (from Koster et al, 2003), (b) Same, but for observational precipitation data (from Koster et al, 2003), (c) Differences in precipitation correlations : (a) minus (b), (d) Differences in slope c between the experiments with biased GCM and OBS forcings. 
Figure List 

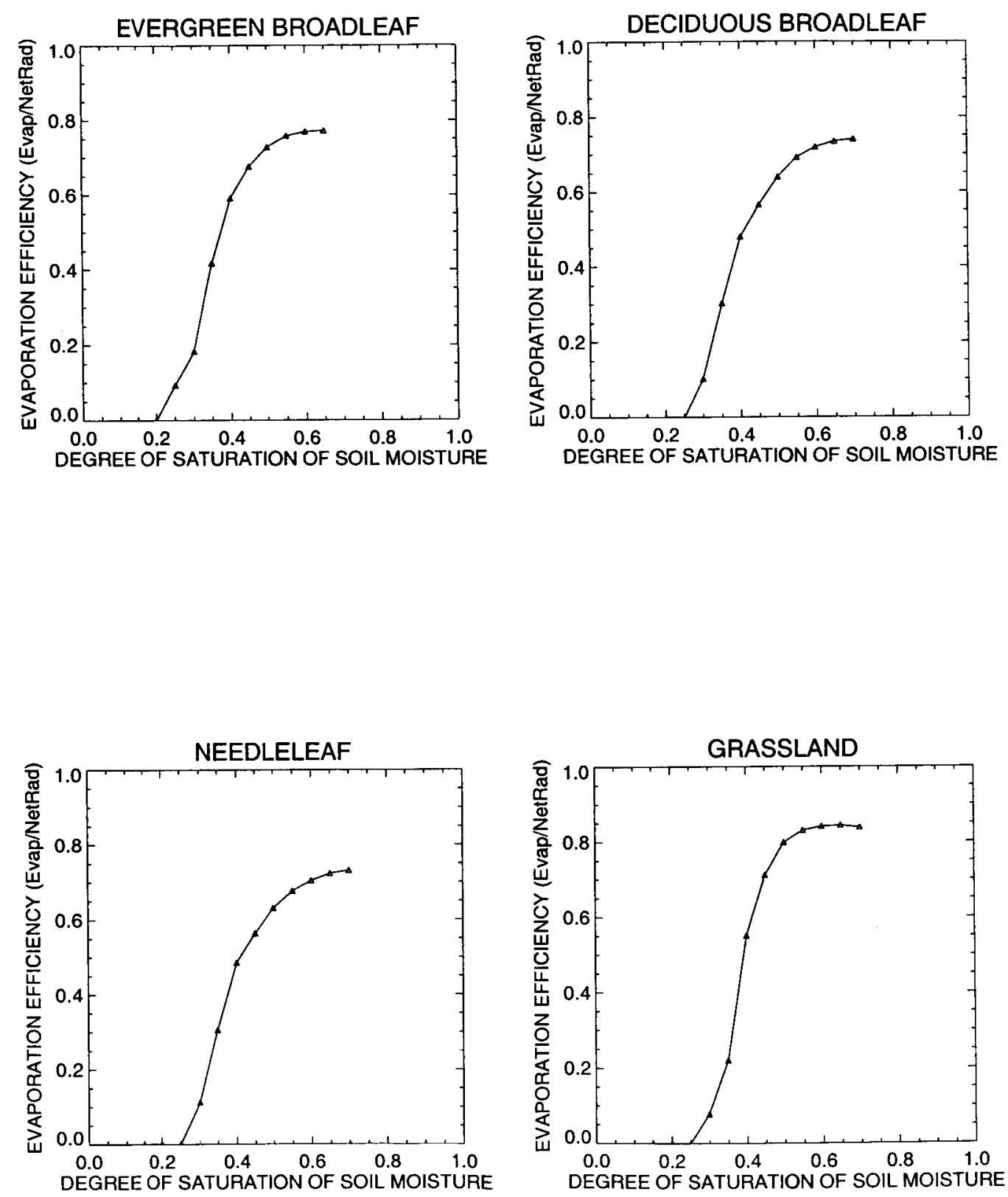

Figure 1: 


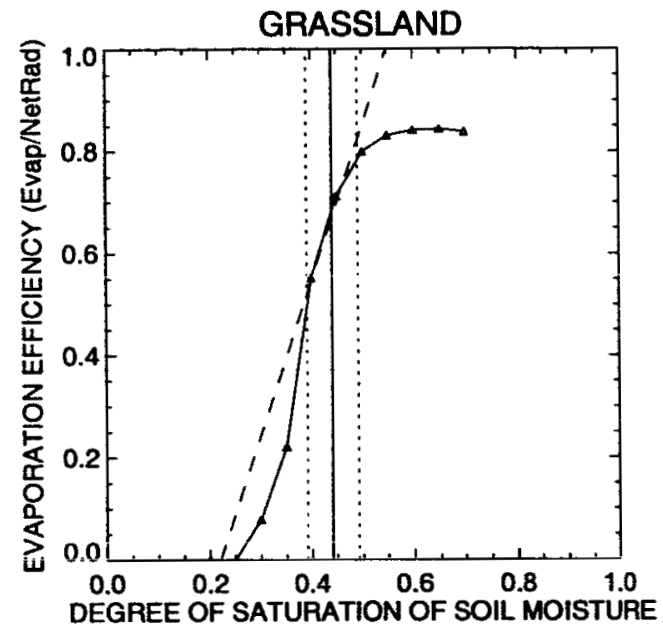

Figure 2: 


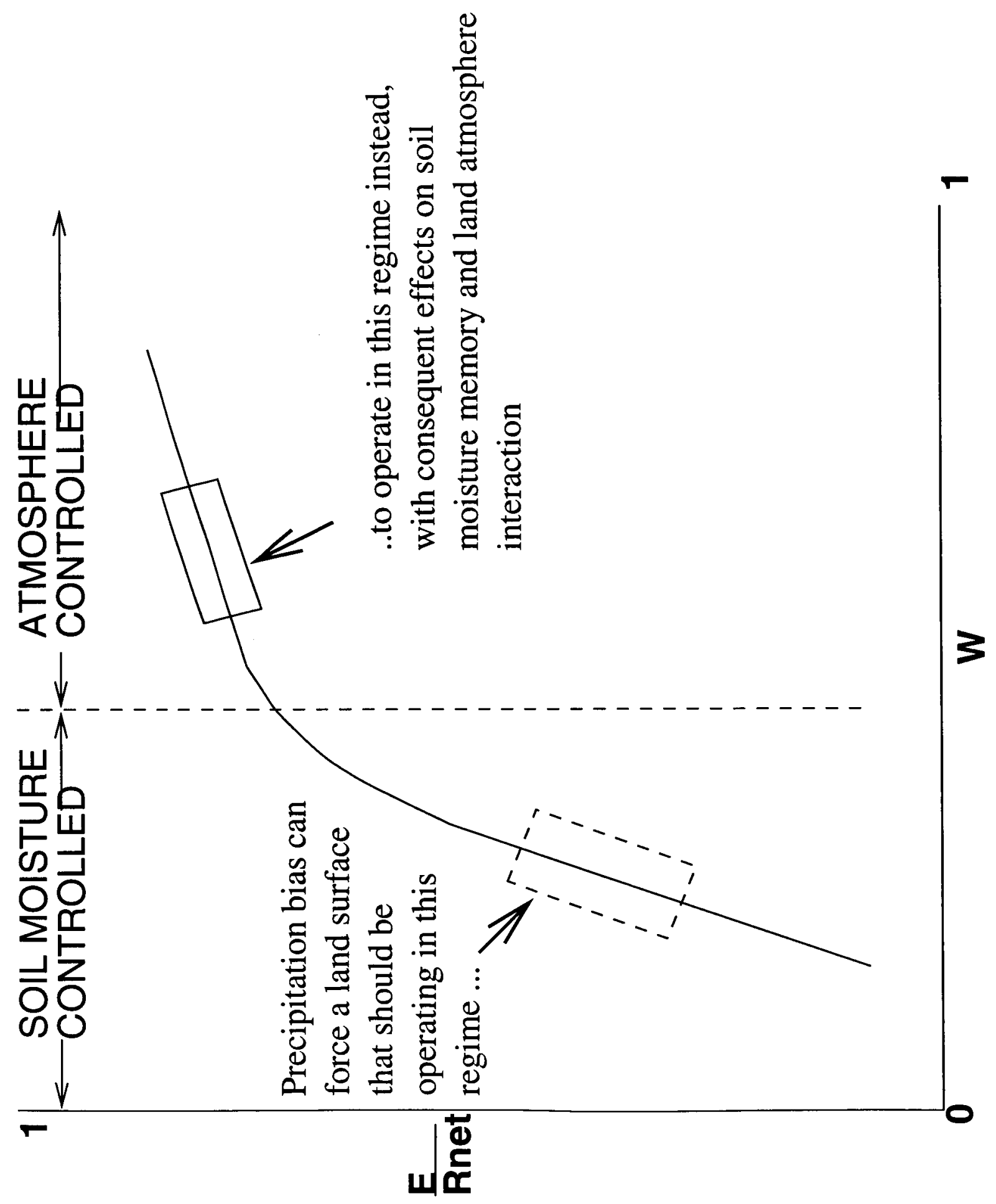

Figure 3: 

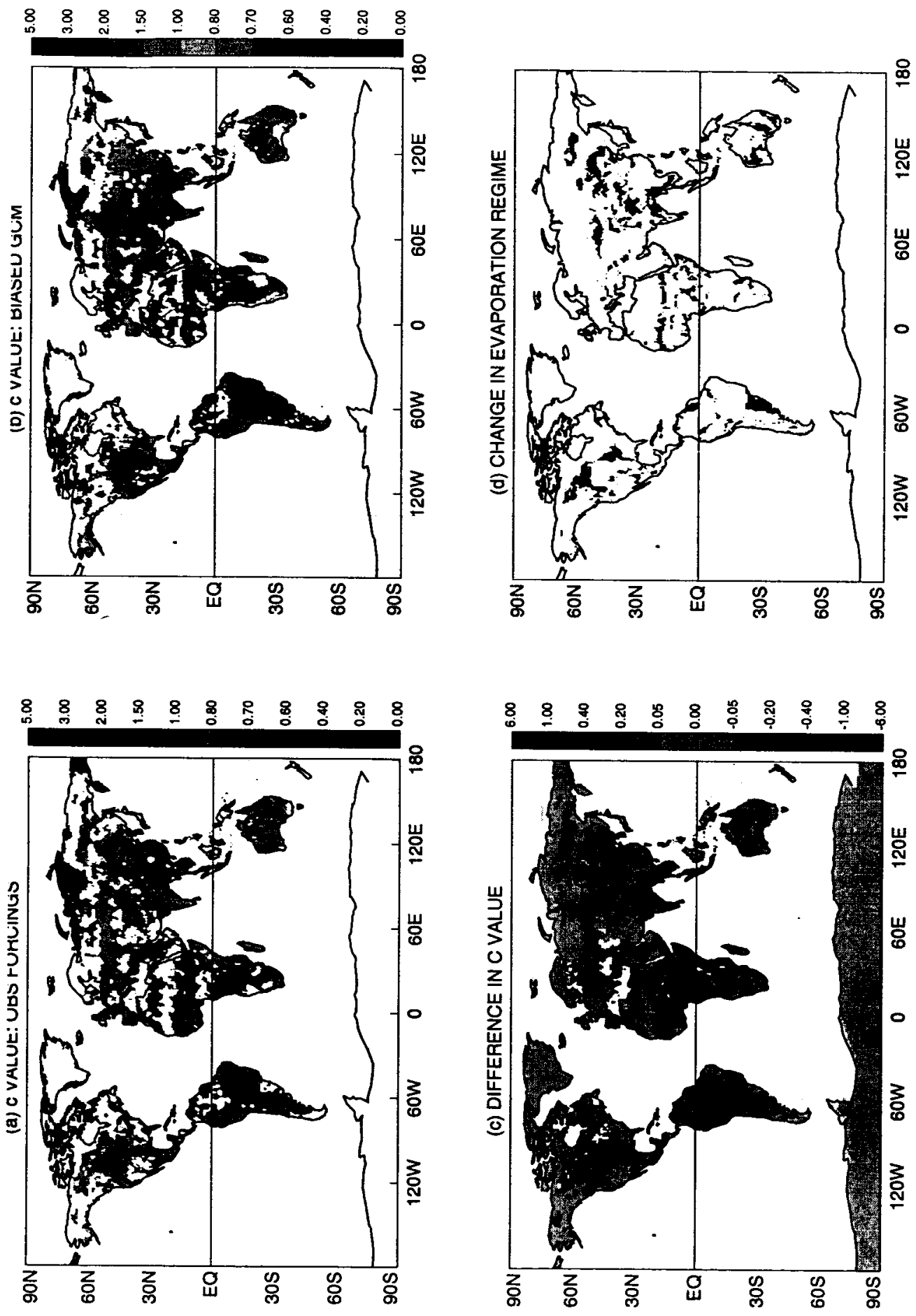

Figure 4: 
(a) PRECIPITATION BIAS: AGCM - OBS (mm/day)

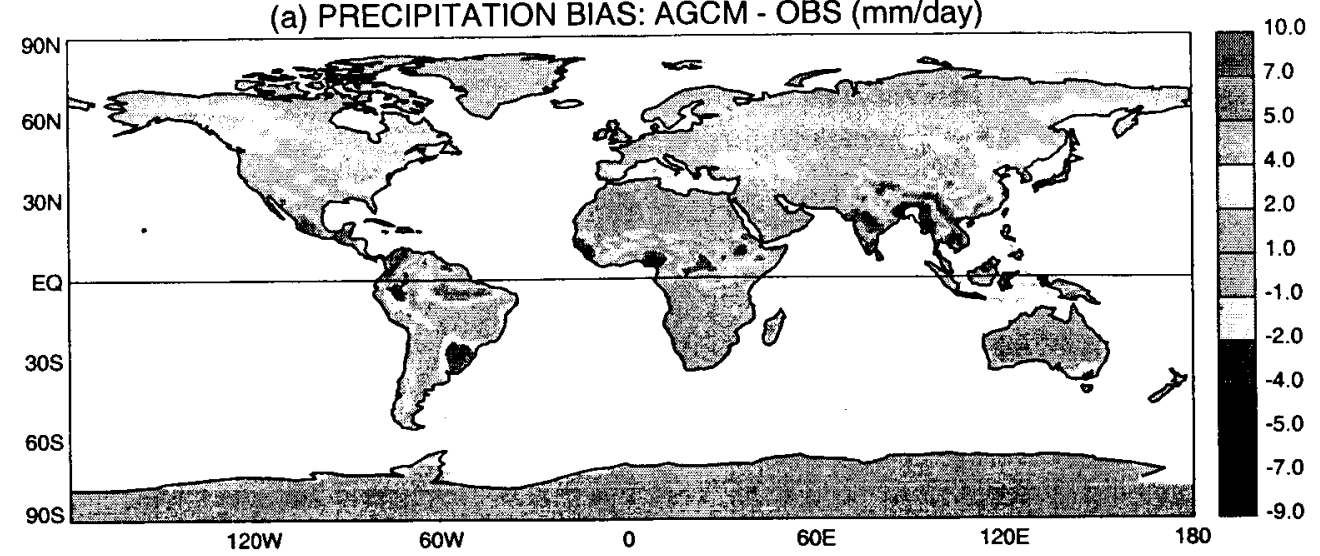

(b) DOWNWARD RADIATION BIAS: AGCM - OBS (W/m2)

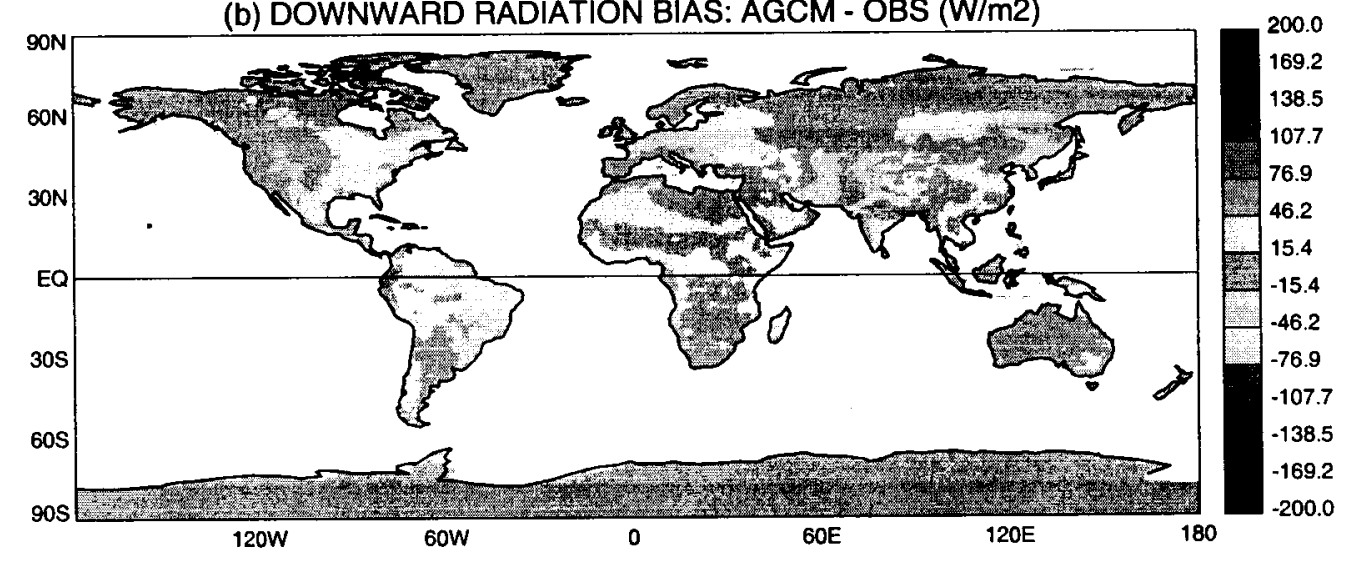

(c) BIASES IN DRYNESS INDEX

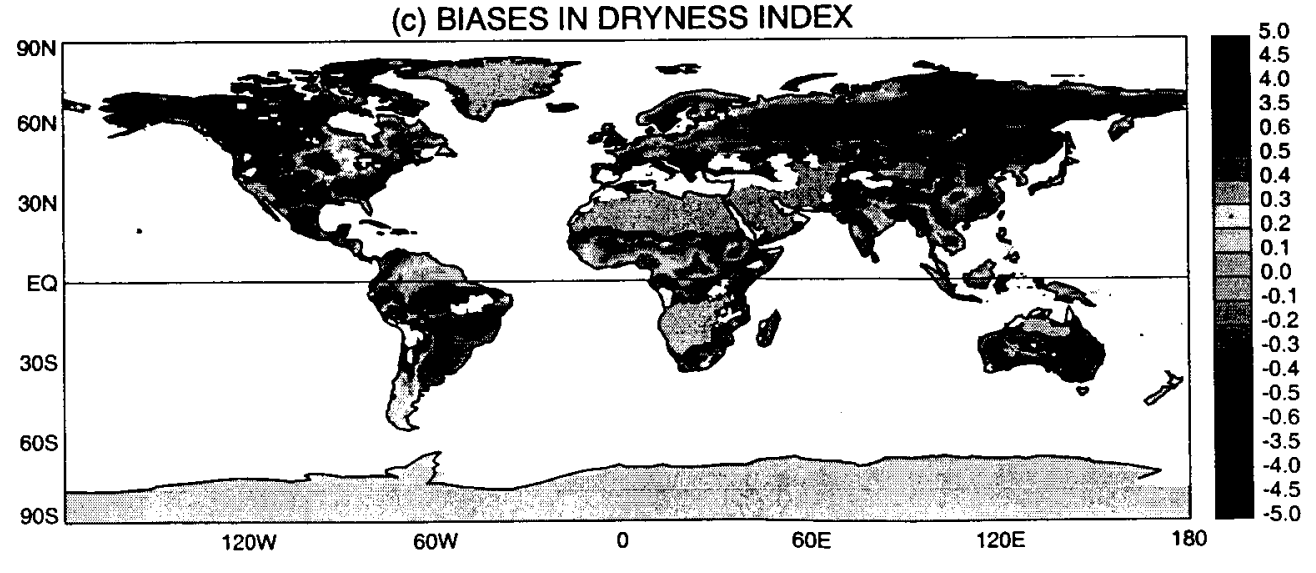

Figure 5: 


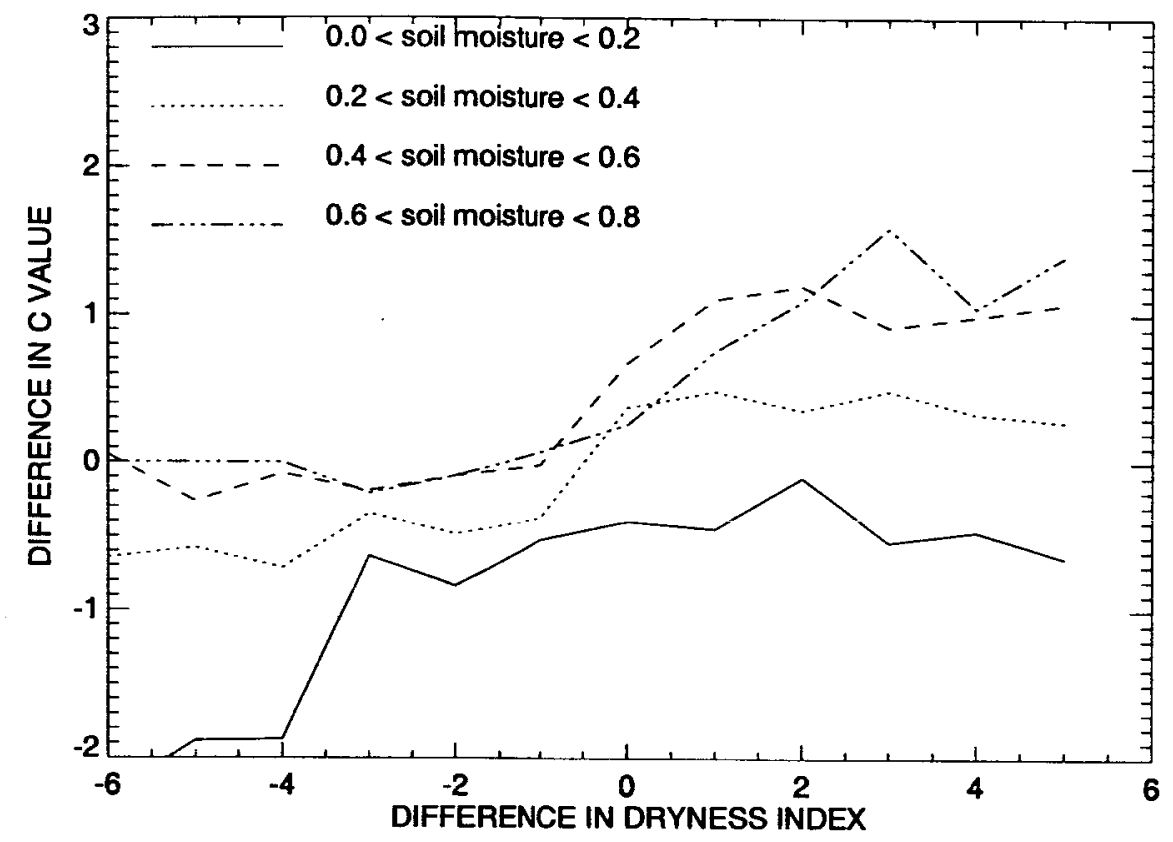

Figure 6: 
(a) ONE-MONTH-LAGGED $\rho$ (JJA) with OBS FORCINGS

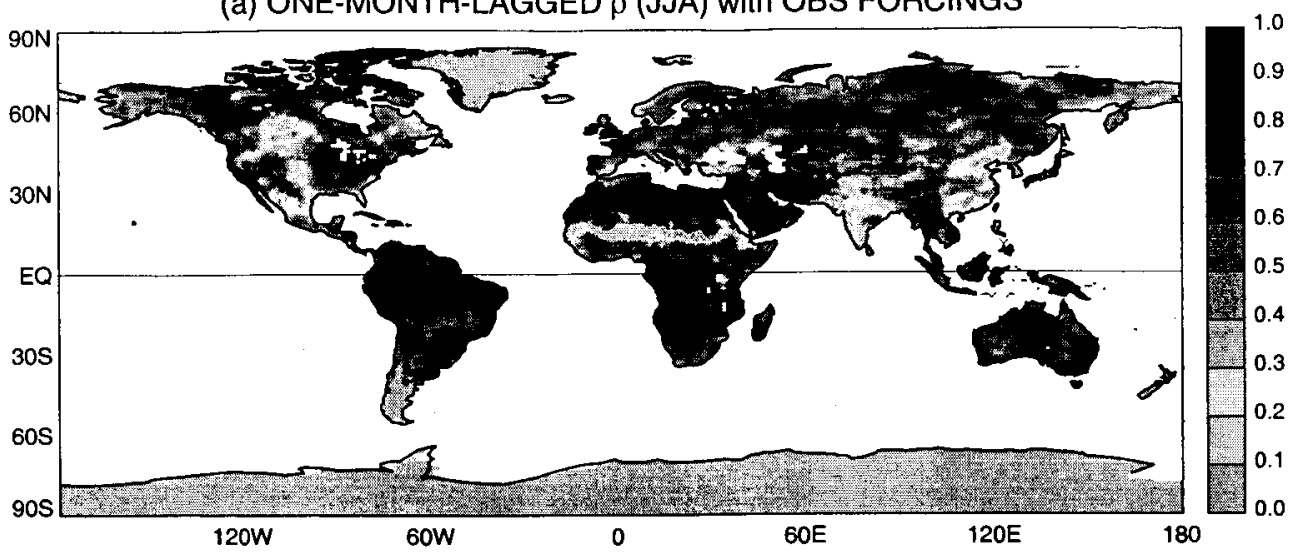

(b) ONE-MONTH-LAGGED $\rho$ (JJA) with BIASED GCM FORCING

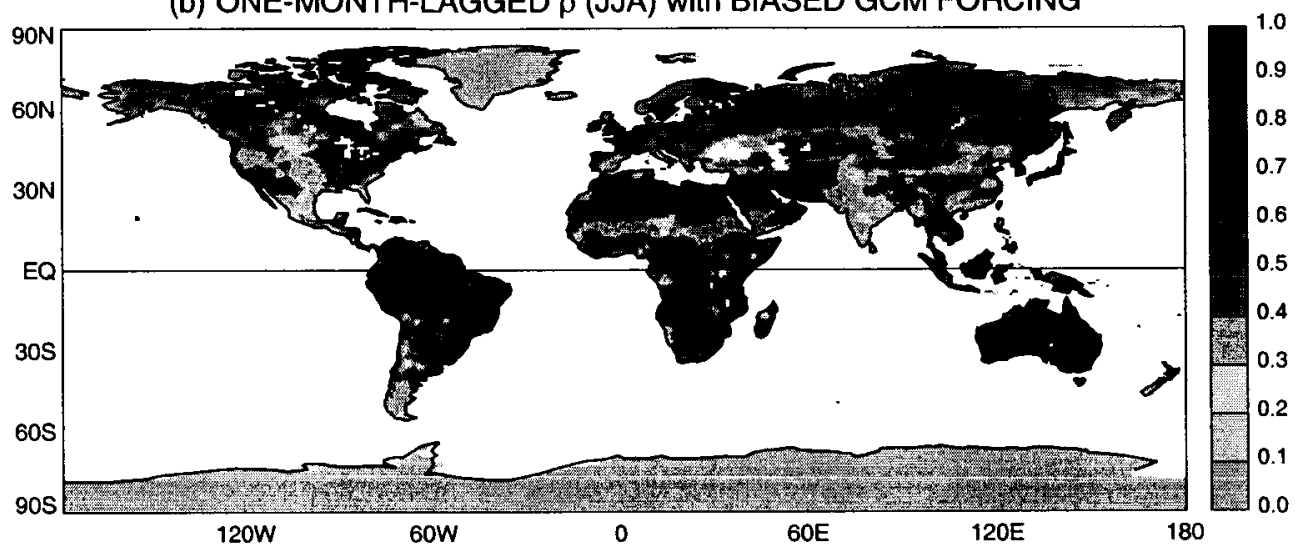

(c) DIFFERENCE IN $\rho$ (JJA): BIASED GCM - OBS

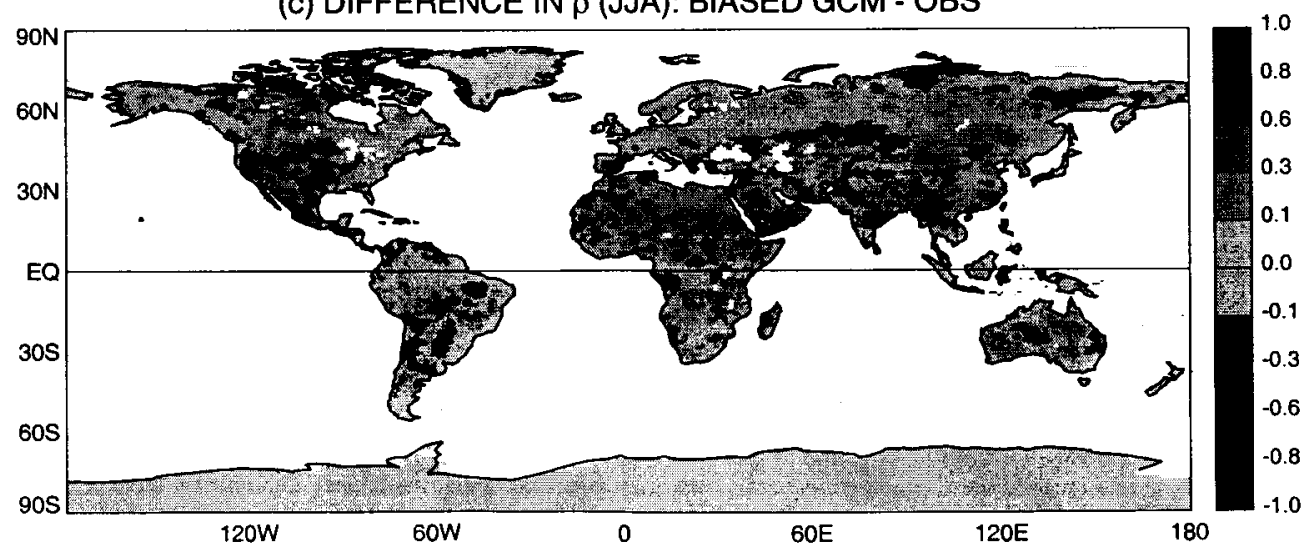

Figure 7: 


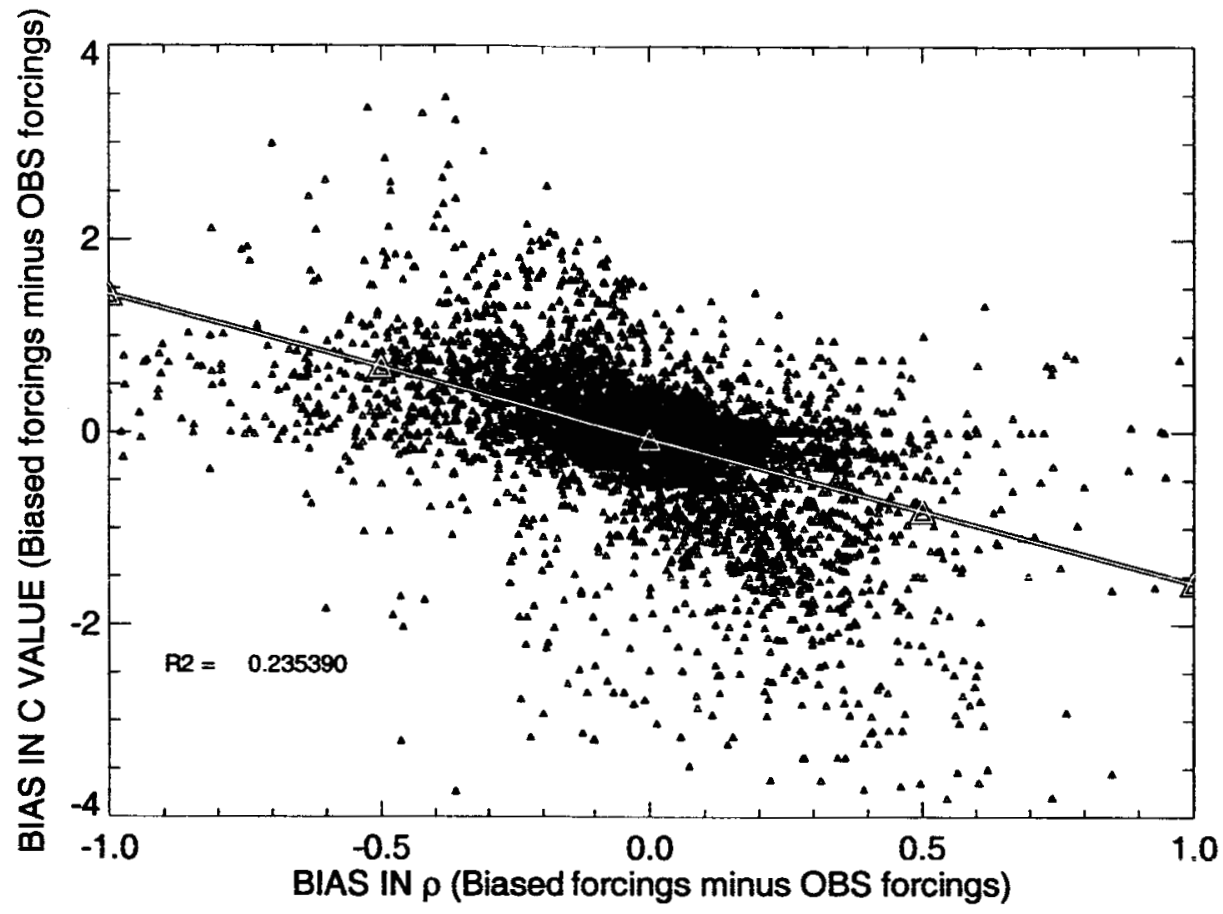

Figure 8: 

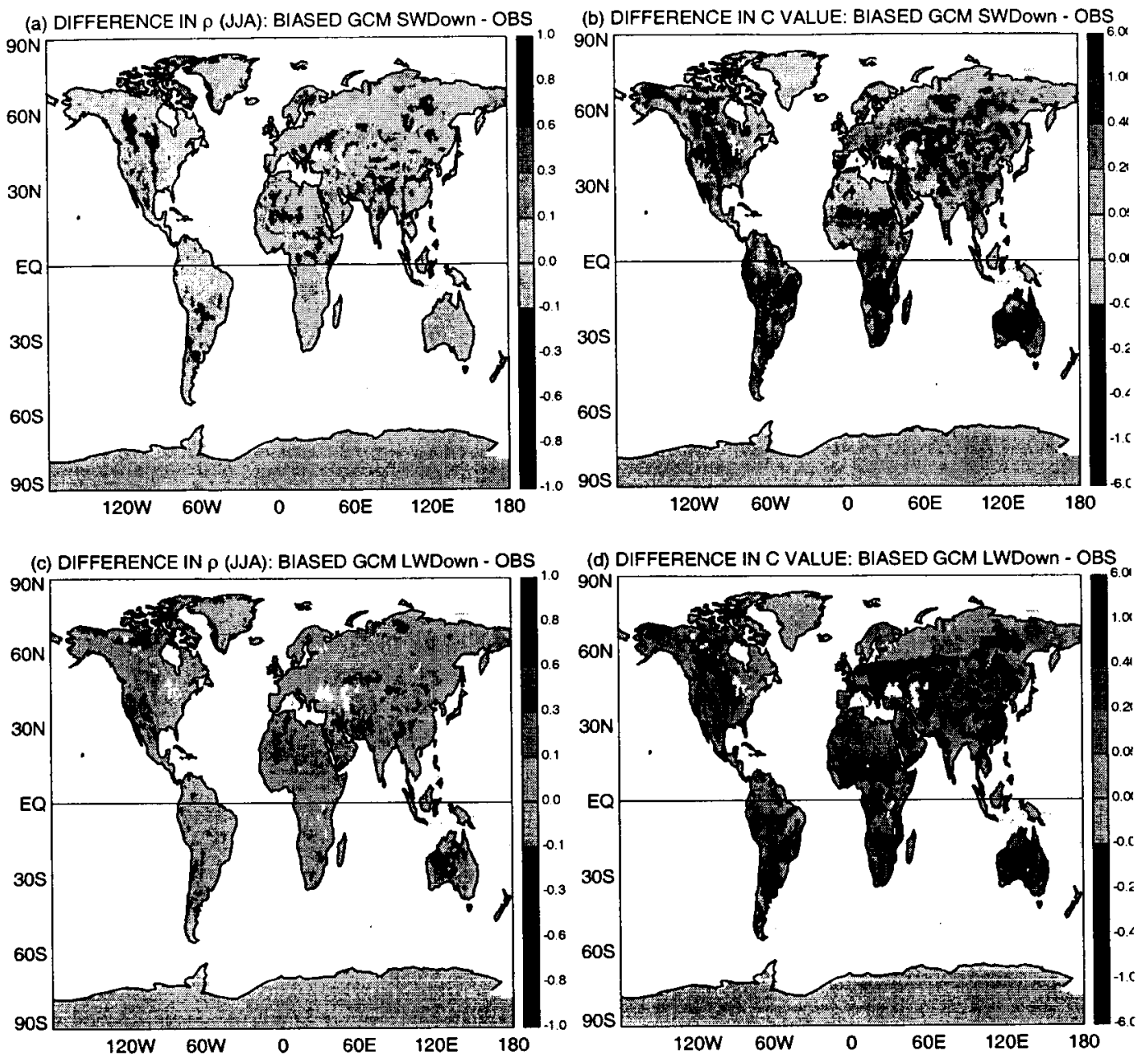

(e) DIFFERENCE IN $\rho$ (JJA): BIASED GCM PreC- OBS
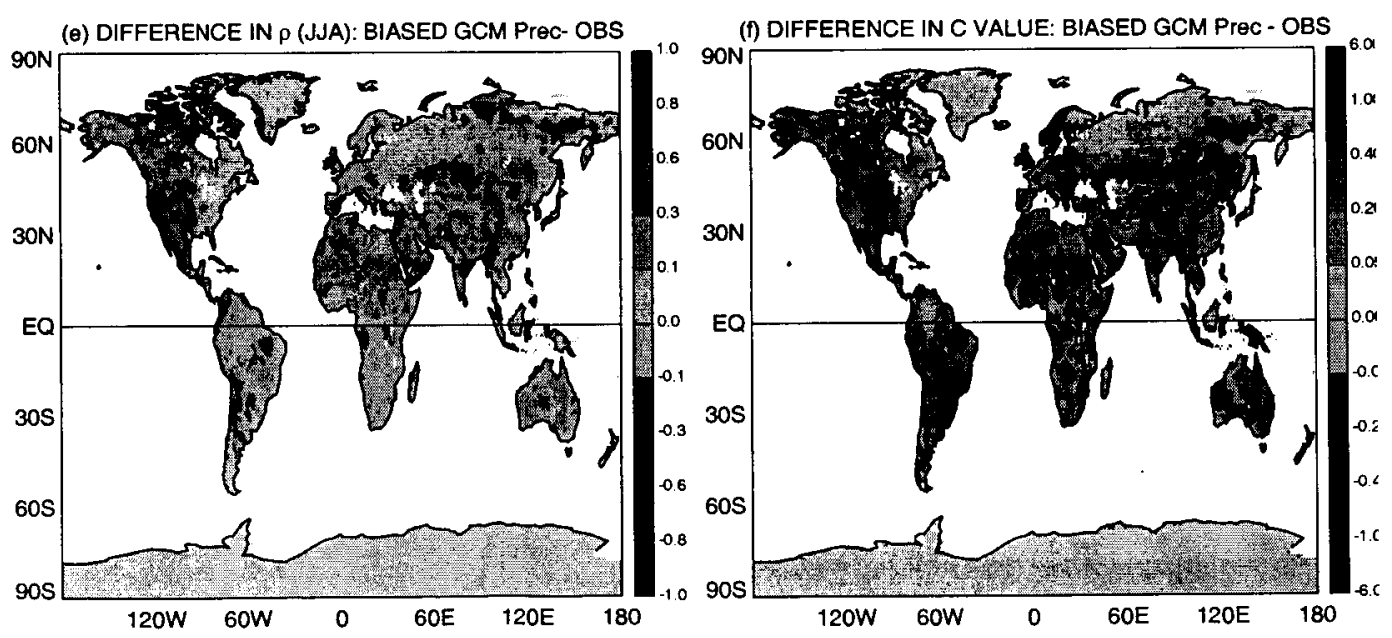

Figure 9: 

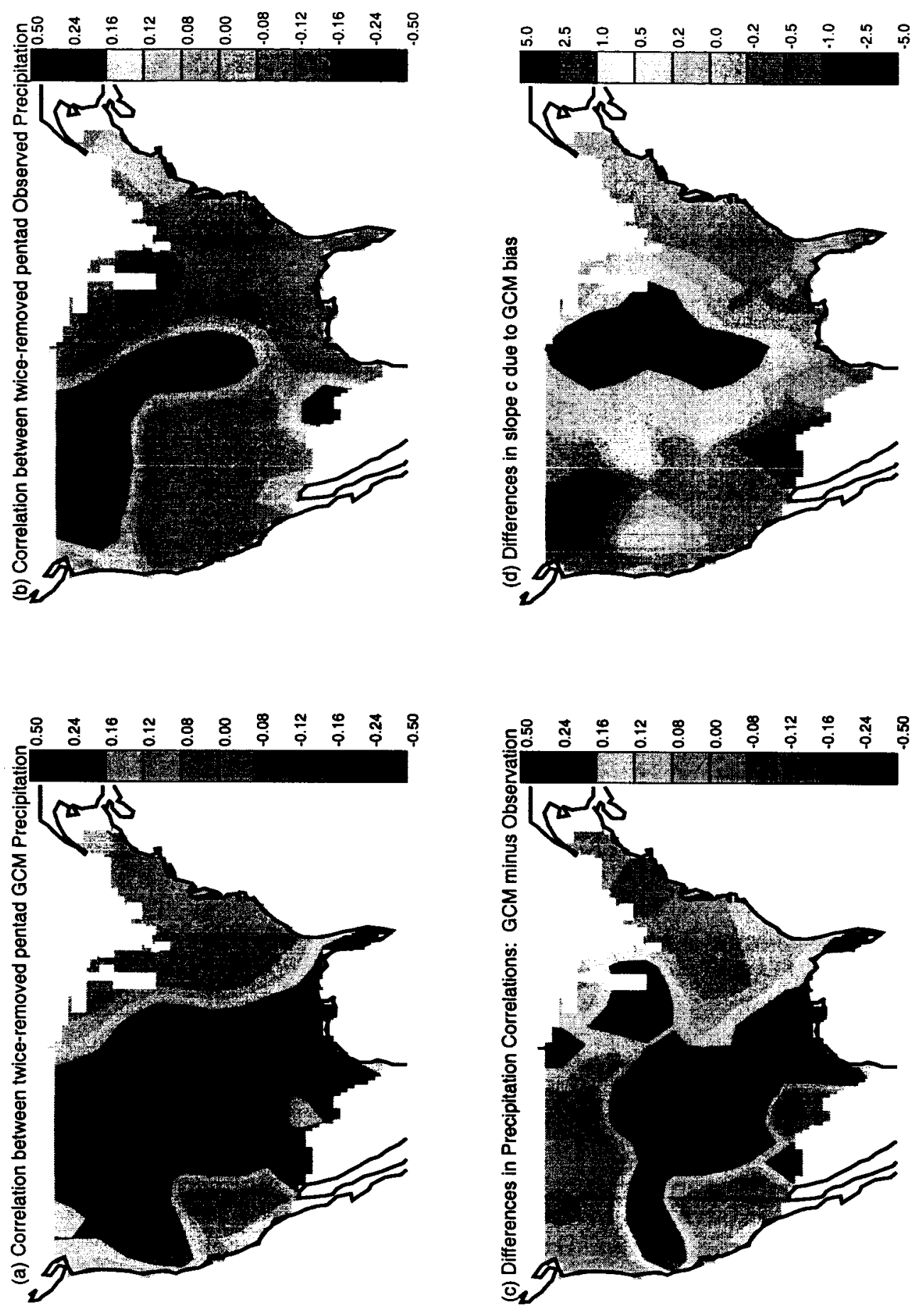

Figure 10: 


\section{Popular Summary:}

"AGCM Biases in Evaporative Regime", by S. Mahanama and R. Koster. (Journal of Hydrometeorology)

Climate models, complex as they are, retain unwanted biases relative to observations. These biases may limit the models' ability to provide useful information about the Earth's climate system. In the present paper, we analyze how such biases limit a climate model's ability to translate initial soil moisture information into skill in precipitation prediction. Two sets of offline land model simulations, one with unbiased atmospheric forcing and one with biased forcing mimicking that of a climate model, are analyzed side by side. The biases affect soil moisture "memory" and the sensitivity of evaporation to soil moisture changes in ways that would indeed affect precipitation prediction skill in a full climate model. 